\title{
When and How to Treat HCV Infection with the New Antivirals before or after Liver Transplantation
}

\author{
Kerstin Herzera, b Guido Gerken ${ }^{b}$ \\ a Department of General, Visceral, and Transplantation Surgery, University Hospital Essen, University Duisburg-Essen, Essen, Germany; \\ ${ }^{b}$ Department of Gastroenterology and Hepatology, University Hospital Essen, University Duisburg-Essen, Essen, Germany
}

\section{Keywords}

Hepatitis C - Liver transplantation - Therapy .

Interferon-free direct-acting antivirals

\section{Summary}

Chronic hepatitis $\mathrm{C}$ virus (HCV) infection is one of the primary causes of hepatocellular carcinoma and liver transplantation (LT). Graft loss due to hepatitis C (HCV) recurrence is a serious problem after LT. Thus, the approval of interferon-free direct-acting antiviral (DAA) regimens has important implications in the LT setting. The findings of controlled trials have confirmed the safety and the excellent efficacy of most DAA combinations, and these findings have been confirmed by reports of high rates of sustained virologic response in the real-life setting. However, data from patients with decompensated cirrhosis who are on the LT waiting list are still scarce and, when available, suggest cautious consideration of whether HCV treatment before LT is beneficial in all cases. Progression of cirrhosis and refractory decompensation result in severely decreasing response rates, the risk of resistance, and reduced Model for End-Stage Liver Disease (MELD) scores despite clinical deterioration, making LT more difficult to achieve. On the other hand, treating $\mathrm{HCV}$ recurrence after $\mathrm{LT}$ is feasible with most of the available DAA combinations. Thus, an important topic of current debate is the establishment of predictors and conditions that can determine whether HCV treatment is best before or after LT. This review article comprehends and discusses recent data and challenges on the treatment of HCV infection in the liver transplant setting.

(c) 2016 S. Karger GmbH, Freiburg

\section{Antiviral Treatment before Liver Transplant}

Hepatitis $\mathrm{C}$ virus (HCV) infection of the graft can usually be avoided only if treatment achieves either a sustained virologic response (SVR) or an on-treatment undetectable HCV RNA level at the time of liver transplantation (LT). Treatment with pegylated interferon (PEG-IFN) plus ribavirin (RBV) can prevent graft infection among patients for whom therapy has achieved viral clearance (undetectable HCV RNA) before LT [1]. However, response rates are mainly influenced by $\mathrm{HCV}$ genotype (poorer results for patients with genotype 1 (GT1) HCV), and the overall efficacy of this therapy is suboptimal (SVR rate, 30\%) [2].

The protease inhibitors (PIs) telaprevir (TPV) and boceprevir (BOC) were the first direct-acting antiviral agents (DAAs); they were approved in 2011 and shed light onto the highly difficult field of peritransplant HCV treatment. These PIs increased the effectiveness of treatment with PEG-IFN plus RBV by as much as $67 \%$ for cirrhosis patients who were on the LT waiting list (WL) and by as much as $62 \%$ for LT recipients [3]. However, the safety of these agents was questionable: serious adverse events (SAEs) were common, and some WL patients died. Therefore, the proportion of WL patients who may benefit from triple therapy (PEG-IFN, RBV, and TPV or BOC) is small for several reasons: the regimens are limited to patients with HCV GT1, and the range of application remains limited because IFN-based therapies are contraindicated for patients with decompensated cirrhosis. Efficacy rates are very low for cirrhosis patients who have not responded to previous therapy (a common situation among patients awaiting LT), and PI-based regimens for patients with compensated cirrhosis are associated with SAEs and even death. As a consequence, with the recent approval of IFN-free regimens, the use of BOC and TPV is no longer recommended [4].

The introduction of DAA combinations that are effective and safe without IFN has been the crucial step forward in the treatment of chronic HCV. The proof of the concept that eradicating HCV

\section{KARGER}

(c) 2016 S. Karger GmbH, Freiburg

Fax +497614520714
Prof. Dr. med. Kerstin Herzer 
before LT is possible for a large proportion of patients was provided by the results of a phase 2 open-label study involving $61 \mathrm{WL}$ patients who were treated with an IFN-free regimen [5]. Patients who were infected with HCV of any GT and who had cirrhosis (Child-Turcotte-Pugh (CTP) score $\geq 7$ ) or hepatocellular carcinoma (HCC) were treated for as long as 48 weeks with sofosbuvir (SOF) and RBV before LT. For most $(n=30 ; 70 \%)$ of the 43 patients who had HCV RNA levels lower than 25 IU/l before transplant, the therapy achieved SVR 12 weeks after LT (SVR12). Importantly, the study showed that a crucial factor in preventing the recurrence of $\mathrm{HCV}$ was an undetectable viral load for at least 30 days before LT.

Several clinical trials and studies involving real-life cohorts with compensated or decompensated cirrhosis have demonstrated the safety and efficacy of various regimens. The COSMOS trial (a study of TMC435 in combination with PSI-7977 (GS7977) in chronic hepatitis $\mathrm{C}$ genotype 1-infected prior null responders to peginterferon/ribavirin therapy or HCV treatment-naïve patients) assessed the safety and efficacy of SOF in combination with simeprevir (SIM) with or without RBV [6]; this study was paralleled by the large real-life cohort of the Translational Research in Oncology (TRIO) network. In this trial, the combination therapy was administered for 12 or 24 weeks to 167 HCV GT1 patients: 80 with no to moderate fibrosis (F0-F2) who were previous non-responders, and 87 with severe fibrosis or cirrhosis (F3-F4) who were either previous non-responders or treatment-naïve. The overall SVR12 rate was $92 \%$ and remained that high even for patients with decompensated cirrhosis $(n=41)$. In the real-life cohort [7], treatment achieved an SVR rate of $75 \%$ for the subgroup of patients with cirrhosis $(\mathrm{n}=125)$, a rate significantly lower than that for patients without cirrhosis.

Another highly effective IFN-free regimen for patients with HCV GT1 is the fixed-dose combination of SOF and ledipasvir (LDV). The ION-1 and ION-2 trials [8, 9] evaluated the administration of this combination with or without RBV for 12 or 24 weeks to treatment-naive and treatment-experienced patients. In both studies the SVR rate was excellent, irrespective of the presence of cirrhosis. In a pooled integrated analysis of all HCV G1 patients with cirrhosis $(n=513)$ who were treated with SOF plus LDV, neither treatment duration nor the addition of RBV had a significant impact on SVR12 (96-100\%) [10]. For treatment-experienced patients with cirrhosis $(\mathrm{n}=352)$, SOF plus LDV without RBV achieved SVR12 for $90 \%$ of patients after 12 weeks and for $98 \%$ of patients after 24 weeks, whereas SOF plus LDV with RBV achieved SVR 12 for $96 \%$ of patients after 12 weeks and for $100 \%$ of patients after 24 weeks. This finding suggests that RBV or extension of treatment duration plays a beneficial role for these patients.

A recent phase II, randomized, prospective multicenter trial evaluated the administration of a fixed-dose combination of SOF/ LDV plus RBV for 12 or 24 weeks to treatment-naive and treatment-experienced patients with GT1 or GT4 HCV and decompensated liver disease who were awaiting LT [11]. No significant difference in SVR in dependence on treatment duration was observed for the CTP class B patients (87 vs. $89 \%$ ) or for the CTP class C patients (86 vs. $90 \%$ ). Successful HCV therapy improved the patients' clinical and biochemical test results, as documented by an improvement in the Model for End-Stage Liver Disease (MELD) score and an increase in serum albumin levels. Importantly, although the clinical condition of some patients stabilized, it worsened in others, meaning that cirrhosis was already too advanced to improve even though SVR was achieved.

The administration of LDV/SOF plus RBV to 215 patients with decompensated cirrhosis was evaluated in the SOLAR 1 and 2 trials [12]. Response rates for patients with CTP class B liver cirrhosis were nearly $90 \%$ after 12 weeks of treatment and 100\% after 24 weeks. For CTP class C patients, the SVR rate was $88 \%$ after 12 weeks and 50\% after 24 weeks. Evaluation of drug safety showed that 22 SAEs were reported by CTP class B patients and 35 SAEs were reported by CTP class C patients; the most common SAE was anemia due to RBV.

The ALLY trials investigated the safety and efficacy of daclatasvir (DAC) in combination with SOF, and data from patients with advanced liver disease who had received a 12-week combination regimen were recently presented $[13,14]$. Patients who underwent LT during treatment could receive 12 weeks of extended treatment immediately after LT, regardless of treatment duration before transplant. Of the 60 patients with liver cirrhosis who were enrolled, 60\% were treatment-experienced, and most (75\%) had HCV GT1. The distribution of CTP classes was as follows: CTP class A 20\%; CTP class B 53\%; and CTP class C 27\%. MELD scores ranged from 8 to 27 . For these patients with cirrhosis, treatment achieved SVR12 for $83 \%$; the rates of SVR12 were, of course, lower for patients with CTP class C cirrhosis and signs of portal hypertension. SVR12 rates were comparable with regard to previous treatment experience and baseline demographic characteristics. Four patients with cirrhosis underwent LT during treatment; 3 of the 4 received extended treatment after LT, and treatment achieved SVR12 for all 4. No SAEs were reported; the most common adverse events were headache, fatigue, anemia, and diarrhea.

A French multicenter observational study reported on the feasibility and improvement of liver parameters and clinical condition of an SOF-based regimen in 183 patients who were candidates for LT [15].

In all studies, clinical and biochemical improvement occurred in only a proportion of patients with decompensated cirrhosis, even those for whom treatment achieved SVR. A considerable number of patients experienced worsening of clinical condition, which reduced their chance of receiving a transplant even though their MELD score improved during treatment. For patients who begin treatment when they have decompensated cirrhosis or signs of portal hypertension, some investigators report deteriorating clinical condition rather than removal of patients from the WL and improvement in quality of life [14]. So far, only 1 case has been published to be withdrawn from the WL [16]. In the French multicenter cohort, $36 \%$ of the 53 patients listed for decompensated cirrhosis experienced a complete clinico-biological response with the best results reported for CTP class A patients (72\%) and only $25 \%$ in CTP class B and $21 \%$ in CTP class C patients. Only $16 \%$ of pa- 
Table 1. Advantages and disadvantages of antiviral treatment in patients on the waiting list before liver transplantation (LT)

\begin{tabular}{ll}
\hline Advantages & Disadvantages \\
\hline $\begin{array}{l}\text { Improvement of liver function } \\
\text { Withdrawal from LT WL }\end{array}$ & $\begin{array}{l}\text { potential deterioration of liver disease } \\
\text { risk of hepatocellular carcinoma } \\
\text { Beneficial for the organ pool }\end{array}$ \\
$\begin{array}{l}\text { no clinical improvement despite } \\
\text { biochemical improvement / } \\
\text { MELD improvement }\end{array}$ \\
No post-LT recurrence & $\begin{array}{l}\text { reduced chances for cure of } \\
\text { cirrhosis/LT }\end{array}$ \\
Treatment option if LT is & use of anti-HCV-positive organs is \\
contraindicated & more difficult \\
\hline
\end{tabular}

tients could be withdrawn from the WL at the end of follow-up [15]. Currently, the criteria for removing patients from the WL have not yet been determined, and successful HCV treatment before LT is not always associated with clinical and biological improvement. Patients with advanced liver disease and high MELD scores will probably not benefit from viral clearance.

However, if treatment can be started early enough, we can anticipate that the availability of highly effective IFNinterferon-free therapies for HCV infection can bring about a substantial change in the area of end-stage liver disease, just as nucleos(t)ide analogs did for patients with HBV infection. If so, these new therapies will save lives and also reduce the number of patients requiring LT or experiencing HCC. Efficacy results from clinical trials cannot be totally translated to the WL list scenario, because both the waiting time and the treatment duration are unpredictable. More results from real-world cohorts are necessary to allow better determination of which patients have a higher likelihood of experiencing HCV eradication and the benefits of treatment before LT and which patients should instead be treated after LT. A good option for patients who are not likely to benefit from treatment while on the WL is antiviral treatment after LT which has become safe and efficient (table 1).

\section{Antiviral Treatment after Liver Transplantation}

Among patients with actively replicating HCV infection who undergo LT, recurrence of HCV after LT is almost ubiquitous and is usually aggravated by a more rapid disease course than that for immunocompetent patients [17]. This accelerated rate of fibrosis results in substantially lower survival rates for both the allograft and the recipient than among LT patients without HCV infection [18]. A progressed level of fibrosis in the graft (METAVIR F $\geq 2$ ) [19] and occurrence of portal hypertension (hepatic venous pressure gradient $(H V P G) \geq 6$ ) [20] 1 year after LT are well-established predictors of aggressive HCV recurrence. The typical plan for treating HCV infection after LT has been to initiate the administration of PEG-IFN plus RBV once histologic findings confirm damage to the graft. However, overall SVR rates with this treatment have not exceeded $30-40 \%$ [21]. These unsatisfactory results were mainly due to poor tolerance or adverse events, resulting in high rates of treatment discontinuation or, at least, dose reductions. Achieving SVR after LT has a well-documented positive impact on HVPG and on survival rates [22].

After triple therapy with PIs was approved, several studies evaluated the safety and efficacy of such regimens for LT recipients. Most of the patients had advanced-stage fibrosis (METAVIR $\mathrm{F} \geq 2$ ) or cholestatic HCV. SVR12 rates were clearly higher than for previous therapies, ranging between 48 and 62\% [23, 24]. However, the main drawbacks of triple therapy for LT recipients were the high rate of SAEs, leading to treatment discontinuation, and severe drug-drug interactions, especially with the immunosuppressants (ISs).

Currently we are receiving data from multicenter clinical trials, compassionate use programs (CUPs), and real-life cohorts; these trials are using various combinations of oral DAAs to treat HCVinfected LT recipients. The SVR12 rates range from 70 to $96 \%$. The first multicenter open-label study involving LT recipients assessed the safety and efficacy of SOF with RBV for 24 weeks [25]. Of the 40 patients, 16 (40\%) were reported to have cirrhosis, and treatment achieved SVR12 for 28 (70\%). The excellent efficacy and safety profile of this regimen was confirmed by real-world data from SOF CUPs: SVR12 was achieved for 59\% of patients treated for as long as 48 weeks with SOF and RBV, with or without PEGIFN. Interestingly, higher rates of SVR12 were achieved for patients with fibrosing cholestatic hepatitis $(73 \%)$ than for patients with cirrhosis (43\%).

In the SOLAR-I study, patients with GT1 or GT4 HCV were given the fixed-dose combination of LDV/SOF with RBV for 12 or 24 weeks; the treatment achieved high rates of SVR [26]. However, SVR rates were lower for patients with CTP class B or C cirrhosis than for patients with mild disease. Specifically, the SVR rates were $60 \%$ for patients with CTP class C cirrhosis and $67 \%$ for patients with portal hypertension. However, the study included only 8 patients.

The real-life HCV TARGET study assessed the combination of SOF and SIM. This trial, which included 68 LT patients [27], reported a high SVR rate (86\%) even for patients with cirrhosis. Other real-life studies have confirmed the efficacy and safety of this combination [28]: SVR12 was achieved for 91\% of LT recipients after 12 weeks of treatment with or without RBV. In both studies, lower viral declines were shown in GT1a than GT1b patients (83 vs. $95 \%$ and 88 vs. $96 \%$, respectively). Most importantly, in the latter study [24], all patients for whom treatment failed had F3 or F4 fibrosis and HCV GT1a.

The open-label phase II CORAL-I study [29] assessed the efficacy and safety of treatment with ombitasvir/paritaprevir/ritonavir plus dasabuvir and RBV for 24 weeks. This cohort included 34 recipients of orthotopic LT with a METAVIR score of 2 or less and recurrent GT1 HCV infection. The SVR12 rate was excellent at $97 \%$, but interactions were reported with ISs, tacrolimus more often than cyclosporine.

Real-life cohorts and CUPs have reported impressively high rates of SVR for the combination of DAC and SOF, with or with- 
out RBV, even for patients with decompensated cirrhosis or HCV recurrence after LT [30, 31].

The combination of DAC and SIM achieved high response rates in the phase 2 SATURN trial [32] and in real-life studies involving LT recipients [33]. However, several viral breakthroughs and relapses have been reported with this combination.

Regarding safety, across the studies, very few SAEs have been reported. Most deaths occurred among cirrhosis patients and were not related to the treatment drugs. Drug-drug interactions must be carefully considered, especially for patients who have undergone LT and are being treated with ISs [34]. The calcineurin inhibitors and the mechanistic target of rapamycin (mTOR) inhibitors (everolimus, sirolimus) are substrates of cytochrome P450 (CYP). Although the DAAs SOF and DAC do not interact with CYP, other antiviral substances, such as SIM, LDV, and ritonavir-boosted ombitasvir/paritaprevir can cause clinically relevant interactions [35]. Conversely, because of significantly increased plasma concentrations of SIM, the concomitant use of SIM and cyclosporine is not recommended for LT recipients. The combination of ritonavirboosted paritaprevir, ombitasvir, and dasabuvir with RBV requires adjustments in the dosages of tacrolimus and cyclosporine. Interestingly, some investigators report a decrease in trough levels of ISs with the decrease in viral load. Therefore, careful monitoring of IS levels is required.

\section{Conclusion}

Several currently available DAA regimens have achieved high rates of SVR for patients with cirrhosis. However, data from patients with decompensated cirrhosis and on the WL for LT are still scarce but suggest that the decision to initiate HCV treatment before LT must be carefully evaluated. Progressing or decompensated cirrhosis together with portal hypertension seems to severely reduce the effectiveness of treatment. Potential problems include lack of response and development of resistance, limited access to future therapies, and reduced MELD scores that render LT less of an option. We must gain more experience in interpreting predictors that can indicate which patients will benefit from HCV treatment before LT. For other patients, it may be preferable to initiate treatment after LT with safe and effective DAA regimens until such predictors can be validated.

\section{Disclosure Statement}

The authors did not provide a conflict of interest statement.

\section{References}

1 Forns X, Garcia-Retortillo M, Serrano T, Feliu A, Suarez F, de la Mata M, Garcia-Valdecasas JC, Navasa M, Rimola A, Rodes J: Antiviral therapy of patients with decompensated cirrhosis to prevent recurrence of hepatitis C after liver transplantation. J Hepatol 2003;39: 389-396.

2 Berenguer M: Systematic review of the treatment of established recurrent hepatitis $\mathrm{C}$ with pegylated interferon in combination with ribavirin. J Hepatol 2008; 49:274-287.

3 Coilly A, Dumortier J, Botta-Fridlund D, et al: Multicenter experience with boceprevir or telaprevir to treat hepatitis $\mathrm{C}$ recurrence after liver transplantation: when present becomes past, what lessons for future? PloS One 2015;10:e0138091.

4 Pawlotsky JM, Aghemo A, Back D, Dusheiko G, Forns X, Puoti M, Sarrazin C; European Association for Study of Liver: EASL recommendations on treatment of hepatitis C 2015. J Hepatol 2015;63:199-236.

5 Curry MP, Forns X, Chung RT, et al: Sofosbuvir and ribavirin prevent recurrence of $\mathrm{HCV}$ infection after liver transplantation: an open-label study. Gastroenterology 2015;148:100-107.e101.

6 Lawitz E, Sulkowski MS, Ghalib R, et al: Simeprevir plus sofosbuvir, with or without ribavirin, to treat chronic infection with hepatitis $C$ virus genotype 1 in non-responders to pegylated interferon and ribavirin and treatment-naive patients: the COSMOS randomised study. Lancet 2014;384:1756-1765.

7 Dieterich D, Bacon BR, Flamm SL, Kowdley KV, Milligan S, Tsai N, Younossi Z, Lawitz E: Evaluation of sofosbuvir and simeprevir-based regimens in the TRIO network: academic and community treatment of a realworld, heterogeneous population. Hepatology 2014;60: 220 a.
8 Afdhal N, Reddy KR, Nelson DR, et al; ION-2 Investigators: Ledipasvir and sofosbuvir for previously treated HCV genotype 1 infection. New Engl J Med 2014;370: 1483-1493.

9 Afdhal N, Zeuzem S, Kwo P, et al; ION-1 Investigators: Ledipasvir and sofosbuvir for untreated HCV genotype 1 infection. New Engl J Med 2014;370:1889-1898.

10 Younossi ZM, Stepanova M, Saab S, Ahmed A, Lam B, Srishord M, Venkatesan C, Wai H, Henry L: The impact of viral hepatitis-related hepatocellular carcinoma to post-transplant outcomes. J Viral Hepat 2016;23: 53-61.

11 Flamm SL, Everson GT, Charlton M, Denning JM, Arterburn S, Brandt-Sarif T, Pang PS, McHutchison JG, Reddy KR, Afdhal NH: Ledipasvir/sofosbuvir with ribavirin for the treatment of HCV in patients with decompensated cirrhosis: preliminary results of a prospective, multicenter study. Hepatology 2014;60:320a$321 \mathrm{a}$.

12 Manns M, Forns X, Samuel D, Denning J, Arterburn S, Brandt-Sarif T, Dvory-Sobol H, Pang PS, McHutchison JG, Gane E, Mutimer D: Ledipasvir/sofosbuvir with ribavirin is safe and efficacious in decompensated and post liver transplantation patients with HCV infection: preliminary results of the prospective SOLAR 2 trial. Transpl Int 2015;28:21-21.

13 Poordad F, Schiff E, Vierling J, Landis C, Fontana R, Yang R, McPhee F, Hughes E, Noviello S, Swenson E: A phase 3 study (ALLY-1) of daclatasvir, sofosbuvir, and ribavirin for treatment of HCV in advanced cirrhosis or posttransplant HCV recurrence. Transpl Int 2015;28:21-22.
14 Foster GR, Irving WL, Cheung MC, Walker AJ, Hudson BE, Verma S, McLauchlan J, Mutimer DJ, Brown A, Gelson WT, MacDonald DC, Agarwal K; HCV Research, UK: Cohort study of the impact of direct acting antiviral therapy in patients with chronic hepatitis C and decompensated cirrhosis. J Hepatol 2016;64:12241231

15 Coilly A, Pageaux GP, Houssel-Debry P, et al: Improving liver function and delisting of patients awaiting liver transplantation for HCV cirrhosis: do we ask too much to DAA? Hepatology 2015;62:257a.

16 Ruiz I, Feray C, Pawlotsky JM, Hezode C: Patient with decompensated hepatitis $\mathrm{C}$ virus-related cirrhosis delisted for liver transplantation after successful sofosbuvir-based treatment. Liver Transpl 2015;21:408-409.

17 Neumann UP, Berg T, Bahra M, Seehofer D, Langrehr JM, Neuhaus R, Radke C, Neuhaus P: Fibrosis progression after liver transplantation in patients with recurrent hepatitis C. J Hepatol 2004;41:830-836.

18 Forman LM, Lewis JD, Berlin JA, Feldman HI, Lucey MR: The association between hepatitis $\mathrm{C}$ infection and survival after orthotopic liver transplantation. Gastroenterology 2002;122:889-896.

19 Carrion JA, Torres F, Crespo G, Miquel R, GarciaValdecasas JC, Navasa M, Forns X: Liver stiffness identifies two different patterns of fibrosis progression in patients with hepatitis $C$ virus recurrence after liver transplantation. Hepatology 2010;51:23-34.

20 Blasco A, Forns X, Carrion JA, Garcia-Pagan JC, Gilabert R, Rimola A, Miquel R, Bruguera M, Garcia-Valdecasas JC, Bosch J, Navasa M: Hepatic venous pressure gradient identifies patients at risk of severe hepatitis $\mathrm{C}$ recurrence after liver transplantation. Hepatology 2006;43:492-499. 
-21 Berenguer M, Palau A, Aguilera V, Rayon JM, Juan FS, Prieto M: Clinical benefits of antiviral therapy in patients with recurrent hepatitis $\mathrm{C}$ following liver transplantation. Am J Transplant 2008;8:679-687.

22 Carrion JA, Navasa M, Garcia-Retortillo M, GarciaPagan JC, Crespo G, Bruguera M, Bosch J, Forns X: Efficacy of antiviral therapy on hepatitis $\mathrm{C}$ recurrence after liver transplantation: a randomized controlled study. Gastroenterology 2007;132:1746-1756

-23 Burton JR Jr, O’Leary JG, Verna EC, Saxena V, Dodge JL, Stravitz RT, Levitsky J, Trotter JF, Everson GT, Brown RS Jr, Terrault NA: A US multicenter study of hepatitis $\mathrm{C}$ treatment of liver transplant recipients with protease-inhibitor triple therapy. J Hepatol 2014;61: 508-514.

24 Herzer K, Papadopoulos-Kohn A, Achterfeld A, Canbay A, Piras-Straub K, Paul A, Walker A, Timm J, Gerken G: Management of telaprevir-based triple therapy for hepatitis $\mathrm{C}$ virus recurrence post liver transplant. World J Hepatol 2015;7:1287-1296.

25 Forns X, Charlton M, Denning J, McHutchison JG, Symonds WT, Brainard D, Brandt-Sarif T, Chang P, Kivett V, Castells L, Prieto M, Fontana RJ, Baumert TF, Coilly A, Londono MC, Habersetzer F: Sofosbuvir compassionate use program for patients with severe recurrent hepatitis $\mathrm{C}$ after liver transplantation. Hepatology 2015;61:1485-1494.

26 Charlton M, Everson GT, Flamm SL, et al.; SOLAR-1 Investigators: Ledipasvir and sofosbuvir plus ribavirin for treatment of $\mathrm{HCV}$ infection in patients with advanced liver disease. Gastroenterology 2015;149:649659.
27 Sulkowski MS, Vargas HE, Di Bisceglie AM, Kuo A, Reddy KR, Lim JK, Morelli G, Feld JJ, Brown RS, Frazier LM, Fried MW, Nelson DR, Jacobson IM: Safety and efficacy of sofosbuvir (SOF) in combination with simeprevir (SIM) plus ribavirin (RBV) in patients with genotype 1: interim results of a prospective, observational study. Hepatology 2014;60:660a-661a.

28 Pungpapong S, Aqel B, Leise M, Werner KT, Murphy JL, Henry TM, Ryland K, Chervenak AE, Watt KD, Vargas HE, Keaveny AP: Multicenter experience using simeprevir and sofosbuvir with or without ribavirin to treat hepatitis C genotype 1 after liver transplant. Hepatology 2015;61:1880-1886.

29 Kwo PY, Mantry PS, Coakley E, Te HS, Vargas HE, Brown R, Gordon F, Levitsky J, Terrault NA, Burton JR, Xie WG, Setze C, Badri P, Pilot-Matias T, Vilchez RA, Forns X: An interferon-free antiviral regimen for HCV after liver transplantation. N Engl J Med 2014; 371:2375-2382

30 Welzel TM, Petersen J, Ferenci P, Gschwantler M, Herzer K, Cornberg M, Schott E, Berg T, Spengler U, Weiland O, van der Valk M, Geier A, Rockstroh JK, Peck-Radosavljevic M, Zhao Y, Exposito MJJ, Zeuzem S: Safety and efficacy of daclatasvir plus sofosbuvir with or without ribavirin for the treatment of chronic HCV genotype 3 infection: interim results of a multicenter European compassionate use program. Hepatology 2015;62:225a-226a.
31 Herzer K, Welzel TM, Ferenci P, Petersen J, Gschwantler M, Cornberg M, Berg T, Spengler U, Weiland O, van der Valk M, Klinker H, Rockstroh JK, Schott E, Peck-Radosavljevic M, Zhao Y, Exposito MJJ, Zeuzem S: Daclatasvir in combination with sofosbuvir with or without ribavirin is safe and efficacious in liver transplant recipients with $\mathrm{HCV}$ recurrence: interim results of a multicenter compassionate use program. Hepatology 2015;62:341a.

32 Forns X, Berenguer M, Herzer K, Sterneck M, Donato MF, Andreone P, Fagiuoli S, Cieciura T, Durlik M, Calleja JL, Marino Z, Simion A, Shukla U, Verbinnen T, Lenz O, Ouwerkerk-Mahadevan S, Peeters M, Kalmeijer R, Witek J: On-treatment virologic response and tolerability of simeprevir, daclatasvir and ribavirin in patients with recurrent hepatitis $\mathrm{C}$ virus genotype $1 \mathrm{~b}$ infection after orthotopic liver transplantation (OLT): interim data from the phase II SATURN study. J Hepatol 2015;62:S191-S192.

33 Herzer K, Papadopoulos-Kohn A, Walker A, Achterfeld A, Paul A, Canbay A, Timm J, Gerken G: Daclatasvir, simeprevir and ribavirin as a promising interferon-free triple regimen for HCV recurrence after liver transplant. Digestion 2015;91:326-333.

34 Höner zu Siederdissen C, Maasoumy B, Marra F, Deterding K, Port K, Manns MP, Cornberg M, Back D, Wedemeyer H: Drug-drug interactions with novel all oral interferon-free antiviral agents in a large realworld cohort. Clin Infect Dis 2015;62:561-567.

35 Ascha MS, Ascha ML, Hanouneh IA: Management of immunosuppressant agents following liver transplantation: less is more. World J Hepatol 2016;8:148-161. 